\title{
Evaluation of the Performance of a Building Envelope Constructed with Phase-Change Materials in Relation to Orientation in Different Climatic Regions
}

\author{
Eda Köse ${ }^{1}$, Gülten Manioğlu ${ }^{2}$ \\ ${ }^{1}$ Istanbul Technical University, Department of Architecture, Turkey \\ ${ }^{2}$ Istanbul Technical University, Department of Architecture, Turkey
}

\begin{abstract}
Minimizing the effect of climatic conditions and energy consumption in buildings are important issues to be considered in the building design process. Due to the changes in climatic conditions, there is an increase not only in the consumption of heating energy but also cooling energy. Certain passive measures to be taken primarily for the building envelope are necessary in order to reduce energy consumption. Applying a phase-change material on the surface of a building envelope is one of the new approaches for controlling heat transfer through the building envelope during the cooling period. It is known that phase-change materials, which are also considered as modern versions of thermal mass concept, can reduce the of a building's heating and cooling energy consumption. In this study, a unit with $10 \mathrm{~m}$ to $10 \mathrm{~m}$ dimension with one external facade in a 3 storey building was evaluated in two cities, Istanbul and Diyarbakır, in temperatehumid and hot dry climatic regions. In order to reduce heating and cooling loads, a phase-change material was applied on the surface of the building envelope. The thickness of the phase-change material on the applied surface was increased at every step, and different building envelope alternatives were created. Heating and cooling energy consumptions were calculated for different orientations of the external facade. When calculated values are evaluated comparatively, it is seen that as the thickness of the phase-change material increases, the energy loads occurred in the unit decrease gradually. Equally, the performance of the phase-change materials varies depending on the orientation. Therefore, it is possible to determine the optimum thickness and orientation combination of the phase-change material application on a building envelope and reduce heating and cooling energy consumptions.
\end{abstract}

\section{Introduction}

$82 \%$ of the energy consumed in buildings is used for heating [1]. On the other hand, demand for cooling in buildings has been rising fast. Given our dependency on export energy resources, reducing heating and cooling energy in buildings has become a necessity. Reducing heating and cooling energy consumption in buildings is essentially possible by taking correct decision about the variables that affect heating and cooling energy loads in buildings [1]. With its orientation and optical and thermo-physical characteristics the building envelope which is the physical barrier between the exterior and interior environments is one of the most important parameters that affect energy consumption [2]. Building envelopes can be determined according to climatic conditions and therefore can vary from region to region.

Thermal energy storage capacity of Phase-Change Materials (PCMs) which is developed as an alternative to the conventional thermal mass concept is used to reduce heating and cooling energy in buildings. PCMs show varying performances depending on climate types [3]. Thermal energy which PCMs store during daytime and night time and release to the interiors is known to have reducing effect on not only heating energy consumption during heating period but also on cooling energy consumption during cooling period [5]. Based on the studies, PCMs are known to show the best results in areas where the temperature difference between day and night is bigger. In hot climatic regions, with the heat they store during night, PCMs can optimize indoor temperature during daytime. In cold climatic regions, their working principle is to prevent a decrease in indoor temperature. Thus they reduces cooling requirement in hot climatic regions. They tend to reduce heating energy in cold climatic regions [6-7].

Thermal energy storage methods are classified into two groups, the first being sensible heat and the other is latent heat. Sensible heat is the storage of energy by using the heat storage capacity of a material, either solid or liquid. By increasing the temperature of the heat storage material the energy is stored as sensible heat. During the storage of sensible heat, ambient temperature changes. Latent heat is the heat that a material receives from or gives to the environment during phase change. Storage capacity required for latent heat storage methods 
is smaller than that required for sensible heat. The relationship between sensible heat and latent heat is shown in Figure 1 [3] [8].

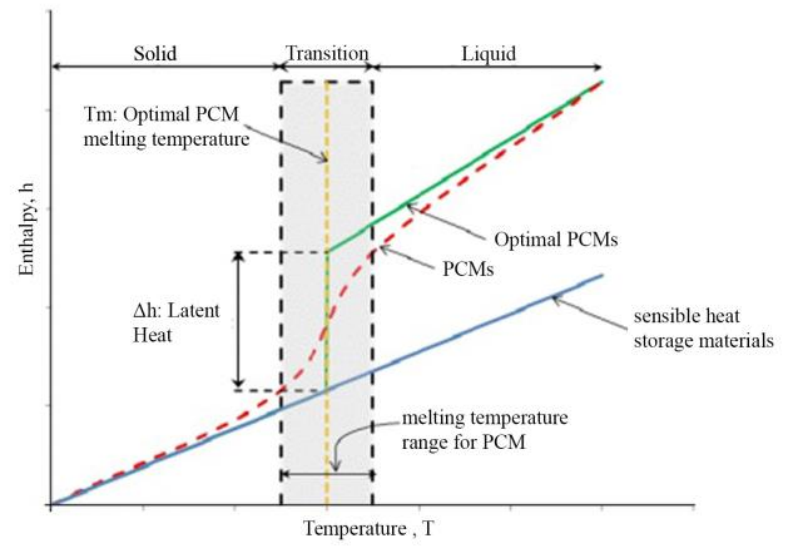

Fig. 1. Sensible heat - Latent heat relationship

Heat storage capacity of PCMs per unit mass or unit volume is higher than the storage capacity of sensible heat storage materials. Since PCM's temperature remains almost constant during the energy storage process, they are quite suitable for energy storage and recovery at a constant temperature. Another thermo-physical property of PCMs is their melting and solidification temperatures [5-10].

Melting temperature is the temperature at which a material converts from the solid phase to the liquid phase The most suitable melting temperature for PCMs is the temperature which is the closest to the indoor temperature.

Solidification temperature is the temperature at which a material converts from the solid phase to the liquid phase. Based on the findings of the applications, the most suitable PCM is the one which has a solidification temperature which is the closest to the indoor temperature [4] [11].

PCMs act as a storage area that allows conservation of heat in the building component they are applied. PCMs are used in buildings due to their capacity to provide high energy storage intensity. Thus they can be considered as a passive method to achieve better indoor comfort conditions, which also increases the thermal mass of the application surface [8].

There are many studies on PCM applications on buildings. Among those; Al-Saadi and Zhai[3], Kalnæs and Jelle [4], Kuznik [5], F. Souayfane, F. Fardoun and P. H. Biwole [6], Köse and Manioğlu [7-8] claim in their studies that PCMs optimize indoor comfort conditions and reduce energy consumption through theirs thermal storage capabilities [9-10] In addition to the above mentioned studies, in this study, heating and cooling energy consumptions when PCM is applied on external walls for a middle unit with different orientations and in different climatic regions (temperate-humid, hot-dry) were calculated using a simulation program and evaluated using comparative analyses.

\section{Method}

In this study, several alternatives for building envelopes were developed to reduce heating and cooling energy consumption and ensure indoor comfort conditions. These alternatives were applied on a building in Istanbul and Diyarbakır and evaluated using Design Builder program. Design Builder is a user friendly visual interface program that uses Energy Plus program as the simulation motor, which is an integrated simulation program.

\subsection{Determining Building Specific Variables}

Evaluations were made for Istanbul representing temperate-humid climatic region and Diyarbakir for hotdry climatic region. However, Istanbul and Diyarbakir are included in the same Degree-Day Region according to the standard TS-825 'Thermal insulation requirements for buildings'. Therefore, for these two cities, overall heat transfer coefficient values which should be provided by building envelopes were determined based on upper limits recommended by the regulation (table 1). In this study, building envelope options with PCM applications were evaluated by repeating the simulations for the cities representing temperate-humid (Istanbul) and hot-dry (Diyarbakır) climatic regions. Thus PCM performance was evaluated in relation to heating and cooling energy consumption in Istanbul and Diyarbakır. The study was conducted on a three storey building with 18 units (6 units on each floor) and a flat roof with a building footprint of 20x30 meters on a flat land. In order to make comparative evaluations, transparency ratio for large façades of the building was taken as $30 \%$ and for smaller façades as $0 \%$. The middle apartment on the first floor was chosen as the reference unit and simulations were repeated for eight different directions (North, Northeast, East, Southeast, South, Southwest, West and Northwest) by applying PCMs on the external wall layers. The building used in the study is shown in figure 2 .
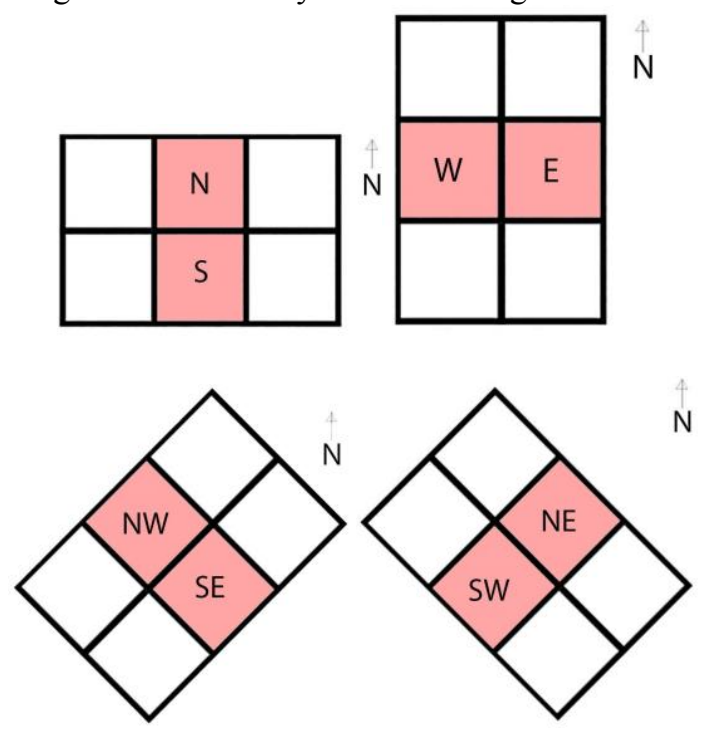

Fig. 2. Different orientations of the building used in the study 
In order to evaluate the performance of the external wall of the unit depending on the PCM material and orientation, all internal walls and floors were accepted that there is no heat transfer (adiabatic). Each building envelope alternative developed was evaluated separately for every orientation. To evaluate heating and cooling energy consumption performance of the building envelope; building envelope alternatives

-with no PCM (A0) and

-with PCM with a thickness ranging from $1 \mathrm{~cm}$ to $5 \mathrm{~cm}$ with $1 \mathrm{~cm}$ increment were created. (A1, A2, A3, A4, A5).

Overall heat transfer coefficient of transparent component was taken as $\mathrm{U}=1.77 \mathrm{~W} / \mathrm{m}^{2} \mathrm{~K}$ in all calculations. The building envelope layering details are shown in Table 1.

\subsection{Determining variables in calculations}

In this study the advanced numerical modelling method, Design Builder 5.5.0.012 application software tool was used to evaluate energy efficiency of phase-change materials with different orientation. Design Builder is a dynamic thermal simulation software program that uses "finite difference method". Thus it is possible to analyse thermal performance of phase-change materials. The model created is shown in figure 3.

Table 1. Layering details of the building envelope

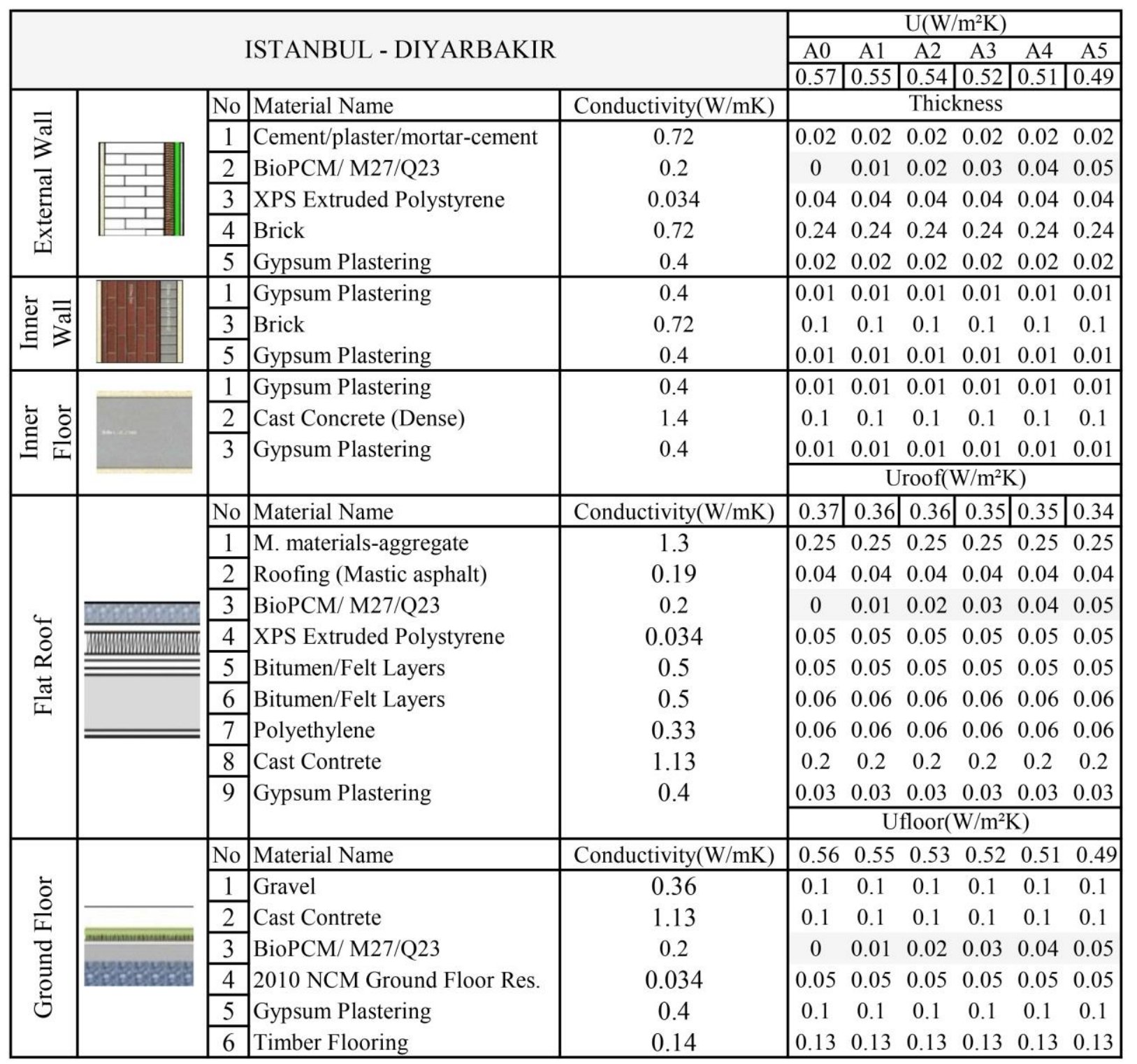

In calculations, the comfort value for indoor air temperature was accepted as $21^{\circ} \mathrm{C}$ for heating and $19^{\circ} \mathrm{C}$ as the lower limit value to turn on the heating system; as $26^{\circ} \mathrm{C}$ for cooling and $28^{\circ} \mathrm{C}$ as the upper limit value to turn on the cooling system.
In this study, a PCM called BioPCM/M27/Q23 which is included in the material library of Design Builder simulation program was used. $1970 \mathrm{~J} / \mathrm{kg}-\mathrm{K}$ was used as the sensible heat value of this material. 
Temperature-Enthalpy relationship of the material is shown in figure 4.

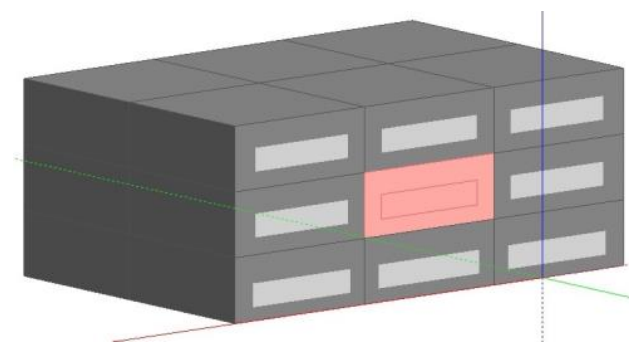

Fig. 3. Building Model

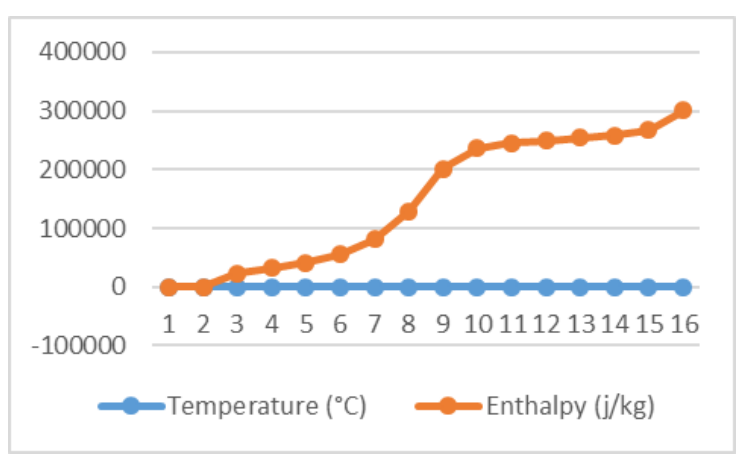

Fig. 4. Temperature-Enthalpy Relationship of BioPCM/M27/Q23

\subsection{Calculation of Annual Heating, Cooling and Total Loads in the Study Units}

Annual values for heating, cooling and total energy consumptions in units were calculated for Istanbul and Diyarbakir in order to evaluate the effect of PCM on the units depending on the orientation. Heating and cooling energy consumption values for both cities are shown in Table 2 and total energy consumption values are shown in Table 3 and 4.

When we look at the heating energy consumption of the cities; A5 alternative was the alternative with the lowest consumption which was in direct proportion with the increasing PCM thickness. When heating energy consumptions of Istanbul and Diyarbakır were compared according to orientation, the lowest heating energy consumption for all building envelope alternatives was achieved in south direction. In Istanbul, heating energy consumption increases in the following order: S, SW, SE, W, E, NW, NE, N whereas Diyarbakır, heating energy consumption increases in the following order: $\mathrm{S}$, SW, SE, W, E, NE, NW, N. For heating energy; the orientation at which PCMs showed the best performance for both cities was south with $3.17 \%$ decrease in Istanbul and $3.67 \%$ decrease in Diyarbakır.

When cooling energy consumptions of Istanbul and Diyarbakır were compared according to orientation, the lowest cooling energy consumption for all building envelope alternatives was achieved in the north direction. In Istanbul, cooling energy consumption increases in the following order: N, NE, NW, S, E, W, SE, SW. whereas in Diyarbakır, cooling energy consumption increases in the following order: N, NE, NW, S, SE, E, SW, W. For cooling energy; the best option was A0 facing north in Istanbul and A5 facing north in Diyarbakır. Due to thereason that PCMs increase cooling energy consumption in Istanbul, none of the orientations showed good performance. In Diyarbakır the orientation at which PCM showed the best performance was northeast with $0.38 \%$ decrease.

Heating energy consumption decreased however cooling energy consumption increased with PCM applications in Istanbul. The lowest heating energy consumption was achieved in south orientation and a decrease of $3.17 \%$ was noted in alternative A5 compared to the alternative A0. The lowest cooling energy consumption was achieved in north orientation and an increase of $1.25 \%$ was noted in alternative A5 compared to the alternative A0. In Diyarbakır, both heating and cooling energy consumptions decreased with PCM use. The lowest heating energy consumption was achieved in south orientation and a decrease of $3.67 \%$ was noted in alternative A5 compared to the alternative A0. The lowest cooling energy consumption was achieved in north orientation and a decrease of $0.3 \%$ was noted in alternative A5 compared to the alternative A0.

In Istanbul and Diyarbakır which are accepted to be in the same Degree-Day Region according to the standard TS-825; heating load values were always higher in Istanbul except for N, NE and NW directions. Cooling load values were always higher in Diyarbakır in all orientations.

When we look at the total energy consumption of these cities, A5 in south orientation was the alternative with the lowest consumption for both cities. In Istanbul, total energy consumption increased in the following order: S, N, SE, SW, NE, NW, E, W. wheras in Diyarbakir, total energy consumption increased in the following order: S, SW, SE, N, NE, NW, E, W The lowest heating energy consumption in Istanbul was achieved in south orientation and a decrease of $1.77 \%$ was noted in the alternative A5 compared to the alternative A0. The decrease in Diyarbakır in the same orientations was $1.8 \%$. For total energy consumption; the orientation at which PCMs showed the best performance for both cities was north with $1.94 \%$ decrease in Istanbul and $1.90 \%$ decrease in Diyarbakır. In Istanbul and Diyarbakır which are accepted to be in the same DegreeDay Region according to the standard TS-825; total energy consumption was always higher in Diyarbakır in all orientations.

When total energy consumptions in different orientations were compared, there were orientation and building envelope alternatives in Istanbul and Diyarbakır with energy consumptions that were very close with only 0-3 kWh difference. (Istanbul: The alternatives N-A0 and SE-A2, N-A1 and SE-A3, NE-A0 and NW-A3, NE$\mathrm{A} 2$ and NW-A4 and A5, NE-A4 and A5 and SW-A0 and E-A4 and A5. Diyarbakır: The alternatives NE-A0 and NW-A3, SE-A4 and A5 and SW-A3, W-A4 and NW$\mathrm{A} 0)$. 
Table 2. The ratio of cooling and heating loads to total loads calculated for different orientations in Istanbul and Diyarbakır

\begin{tabular}{|c|c|c|c|c|c|c|}
\hline \multicolumn{7}{|c|}{ ISTANBUL } \\
\hline \multirow{7}{*}{$\begin{array}{l}\text { I } \\
\stackrel{\mathfrak{L}}{\mathbf{1}} \\
\text { ○ }\end{array}$} & AO & & 4603. & & If & \\
\hline & A1 & & 4578. & & & 49 \\
\hline & A2 & & 4553. & & 18 & 59 \\
\hline & A3 & 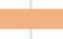 & 4508. & & 18 & \\
\hline & A4 & & 4486. & & 8 & \\
\hline & A5 & & 4486. & & $\varepsilon$ & \\
\hline & $0 \%$ & $20 \%$ & $40 \%$ & $60 \%$ & $80 \%$ & $100 \%$ \\
\hline \multirow{7}{*}{ 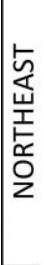 } & AO & 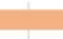 & 4545.46 & & 12 & 33 \\
\hline & A1 & 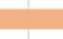 & 4520.60 & & 12 & \\
\hline & A2 & 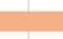 & 4496.66 & & 12 & \\
\hline & A3 & & 4473.70 & & 12 & \\
\hline & A4 & 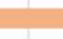 & 4430.00 & - & & \\
\hline & A5 & 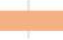 & 4430.00 & & & \\
\hline & $0 \%$ & $20 \%$ & $40 \%$ & $60 \%$ & $80 \%$ & $100 \%$ \\
\hline \multirow{7}{*}{ 㐫 } & AO & 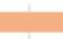 & 61.11 & & $176:$ & \\
\hline & A1 & 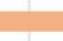 & 37.47 & & 176 & \\
\hline & $A 2$ & & 14.73 & & $176:$ & \\
\hline & $A 3$ & 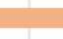 & 51.24 & & 1773 & \\
\hline & A4 & 1 & 51.24 & . & 1773 & \\
\hline & A5 & 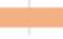 & 51.23 & & 1773 & \\
\hline & $0 \%$ & $20 \%$ & $40 \%$ & $60 \%$ & $80 \%$ & $100 \%$ \\
\hline \multirow{6}{*}{ 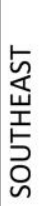 } & AO & 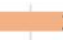 & 8.22 & & 1897. & \\
\hline & A1 & & 5.60 & & 1900. & \\
\hline & $A 2$ & & 3.58 & & 1904. & \\
\hline & A3 & & 2.47 & & 1907. & \\
\hline & A4 & & 3.53 & & 1911. & \\
\hline & A5 & 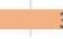 & 3.53 & & 1911. & \\
\hline
\end{tabular}

\begin{tabular}{|c|c|c|}
\hline & \multicolumn{2}{|c|}{ DIYAARBAKIR } \\
\hline AO & 5143.06 & 1925.58 \\
\hline A1 & 5115.02 & 1924.36 \\
\hline A2 & 5088.32 & 1923.79 \\
\hline A3 & 5037.92 & 1921.52 \\
\hline A4 & 5014.31 & 1919.96 \\
\hline A5 & 5014.31 & 1919.96 \\
\hline
\end{tabular}
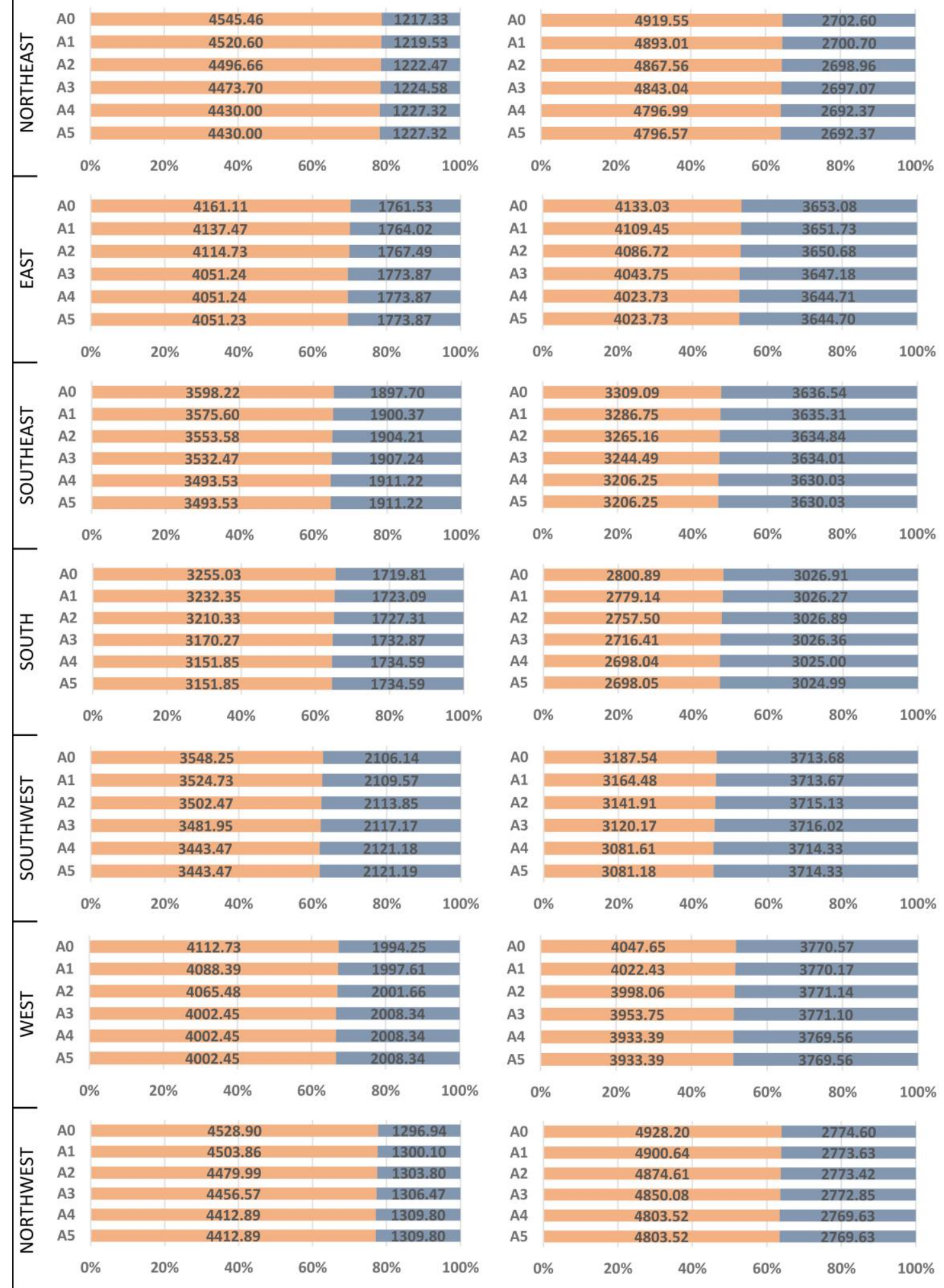

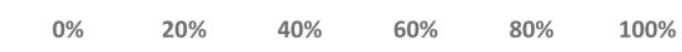

\begin{tabular}{|l|l}
\hline HEATING $(\mathrm{kWh})$ & COOLING $(\mathrm{kWh})$ \\
\hline
\end{tabular}


Table 3. The total energy consumption of the unit in Istanbul in each orientation (kWh)

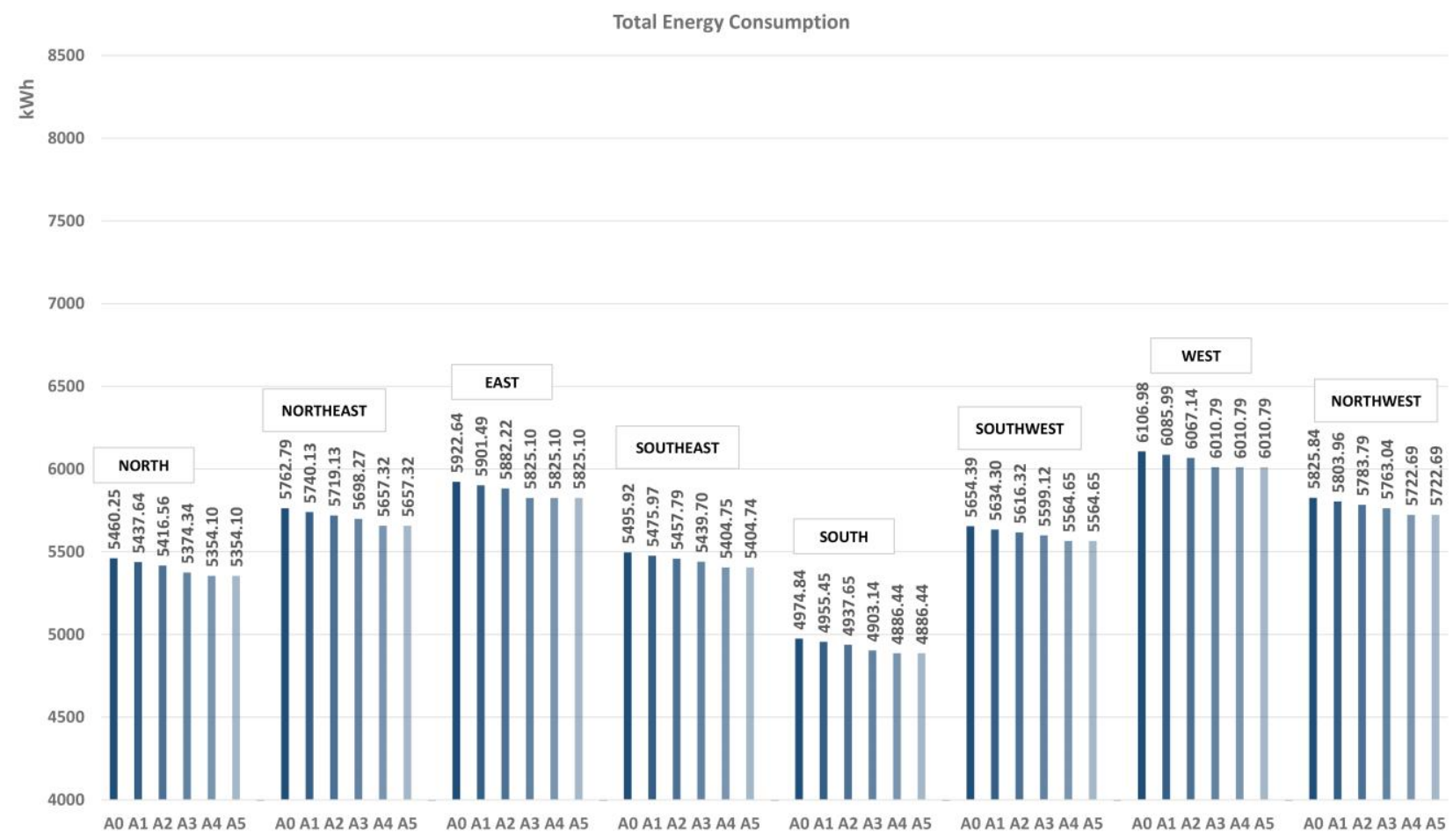

Table 4. The total energy consumption of the unit in Diyarbakır in each orientation $(\mathrm{kWh})$

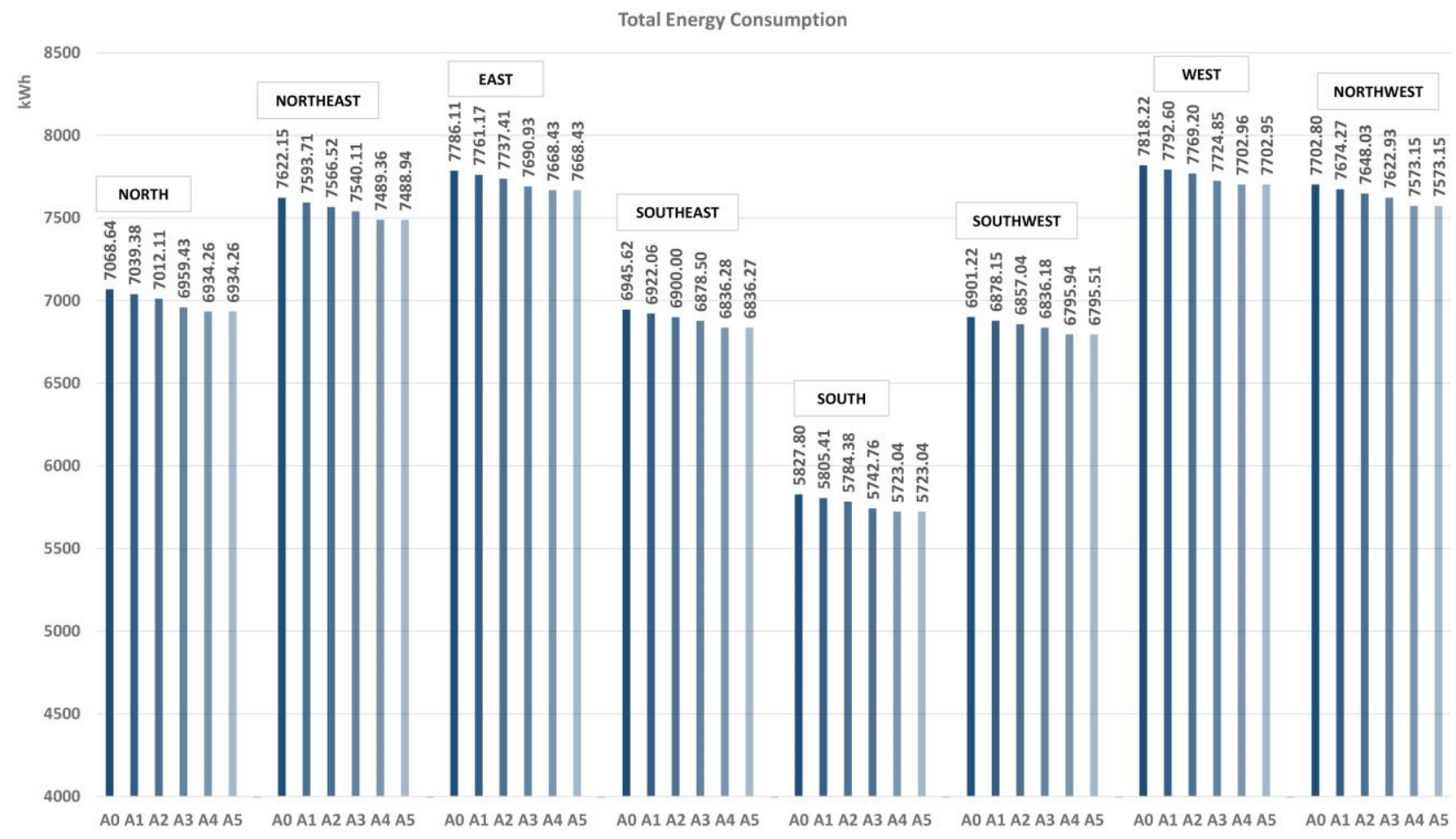




\section{Conclusion}

When we look at the statistics on energy consumption today, the energy used in buildings has a significant share in the total energy consumption. This situation should be evaluated both in relation to energy consumption costs and eco-friendly building design criteria.

This study investigated how the performance of a building envelope changed at different orientations when PCMs with different thicknesses were applied. In the study the effect of PCM application on a building envelope on heating, cooling and total energy consumption of the building was compared and evaluated. The findings of the study are summarized below ;

- When correct design decisions about orientation and thickness of PCM materials are taken, PCM can contribute to a reduction of heating and cooling energy consumption in buildings.

- As PCM thickness increases, its effect on energy consumption in different climatic regions differs. While it reduces all loads in hot climatic regions, it reduces heating and total loads in temperate climatic regions but increases cooling loads.

- When PCM with different thicknesses was used on a building envelope with different orientations, the alternative in which the lowest energy consumption was achieved and the alternative in which PCM performance was the highest (which PCM achieved the highest reduction in energy consumption) could be different.

- Different results in heating, cooling and total energy loads were obtained for the building envelope and orientation alternatives in Istanbul and Diyarbakır which are in the Degree-Day Region 2 according to the standard TS-825 'Thermal insulation requirements for buildings'. In these cities which have different climatic characteristics, the performance of PCM applications also differ.

- It was observed that it is possible to achieve the same energy consumption by using different PCM thicknesses for different orientations. By making correct decisions about PCM thickness it is possible to achieve a balance in energy consumption of units with different orientations in the same building.

Based on this study and its findings; further studies on evaluation of PCM application according to the location of the unit in the building and variation of PCM applications in order to balance energy loads in all units can be recommended.

Acknowledgement: Project Title: All calculations included in this study which was conducted under the master's thesis titled 'Evaluation of the Effect of Phase Change Materials on Heating and Cooling Energy Consumption' (Project ID:41685) were made with the support of SCIENTIFIC RESEARCH PROJECTS UNIT, ISTANBUL TECHNICAL UNIVERSITY.

\section{References}

1. Y. Konuklu, H. Ö. Paksoy, "Faz Değiştiren Maddeler ile Binalarda Enerji Verimliliği", 10. Ulusal Tesisat Mühendisliği Kongresi , (2011).

2. G. Koçlar Oral, G. Manioğlu, "Bina Cephelerinde Enerji Etkinliği ve Isı Yalıtımı”, 5. Ulusal Çatı \& Cephe Sempozyumu, (2010).

3. S. N. Al-Saadi, Z. Zhai, "Modeling Phase Cgange Materials Embedded in Building Enclouse: A Review", Renew. Sustain. Energy Rev., 21, pp.659673, (2013).

4. B. P. Jelle, S. E. Kalnæs, "Phase Change Materials for Application in Energy-Efficient Building", Elsevier Ltd, Chapter 3, pp.57-118, (2017).

5. F. Souayfane, f. Fardoun, P. H. Biwole, "Phase Change Materials (PCM) for Cooling Applications in Buildings: A Review", Energy Building, 129, pp.396-431, (2016).

6. F. Kuznik, D. David, K. Johannes, J. J. Roux, “A Review on Phase Change Materials Integrated in Buildings Walls", Hall archives-ouvertes, 15(1), (2011), pp.379-391.

7. E. Kose, G. Manioğlu, "Evaluation of Performance of Phase Change Materials in Relation to Balanced Distribution of Heating Energy Cost in Residential Building", The Rehva European HVAC Journal, 55(2), pp.52-57, (2018).

8. E. Köse, G. Manioğlu, "Konutlarda Isıtma Enerjisi Maliyetinin Daireler Arasında Dengeli Dağılımı Açısından Faz Değiştiren Malzemelerin Uygulandığı Bina Kabuğu Performansının Değerlendirilmesi”, 3. Ulusal Yapı Fiziği ve Çevre Kontrolü Kongresi, (2018).

9. K. Peippo, P. Kauranen, P. D. Lund, "A multicomponent PCM wall optimized for passive solar heating", Energy and Building, 17, pp.259270, (1991).

10. Jiawei Lei, Jinglei Yang, En-Hua Yang, "Energy Performance of Building Envelopes Integrated with Phase Change Materials for Cooling Load Reduction in Tropical Singapore", Applied Energy, 162, pp.207-217, (2016). 